This item was submitted to Loughborough's Research Repository by the author.

Items in Figshare are protected by copyright, with all rights reserved, unless otherwise indicated.

\title{
A hydrodynamic flow analysis for optimal positioning of surface textures
}

\section{PLEASE CITE THE PUBLISHED VERSION}

https://doi.org/10.1177/1350650117709672

\section{PUBLISHER}

Sage (@ The Authors)

\section{VERSION}

AM (Accepted Manuscript)

\section{PUBLISHER STATEMENT}

This work is made available according to the conditions of the Creative Commons Attribution-NonCommercial 4.0 International (CC BY-NC 4.0) licence. Full details of this licence are available at: https://creativecommons.org/licenses/by-nc/4.0/

\section{LICENCE}

CC BY-NC 4.0

\section{REPOSITORY RECORD}

Morris, Nick, Ramin Rahmani, and Homer Rahnejat. 2019. "A Hydrodynamic Flow Analysis for Optimal Positioning of Surface Textures". figshare. https://hdl.handle.net/2134/24994. 


\title{
A hydrodynamic flow analysis for optimal positioning of surface textures
}

\author{
N.J. Morris*, R. Rahmani and H. Rahnejat \\ Wolfson School of Mechanical, Electrical and Manufacturing Engineering \\ Loughborough University, Loughborough, UK \\ *Corresponding Author: N.J.Morris@ @ lboro.ac.uk
}

\begin{abstract}
The current study uses Reynolds equation and the cross-film flow velocity profile to analytically determine pertinent locations for texture feature positioning in sliding hydrodynamic contacts. The position of textures is shown to have a significant effect on the lubricant film thickness, thus the load carrying capacity and generated friction and power loss. It is shown that textures, residing after the inlet lubricant recirculation boundary and prior to the position of maximum contact pressure enhance film thickness and reduce friction in the contact of real rough sliding surfaces. The methodology is applied to partial surface texturing of a thin compression ring of a high performance race engine, with the predicted results confirming the utility of the expounded analytical technique and its conformance to the findings of others reported in literature. The time-efficient analytical and fundamental approach constitutes the main contribution of the paper to furtherance of knowledge.
\end{abstract}

Keywords: sliding lubricated contacts, surface texturing, micro-hydrodynamics, pressure perturbations

\section{Introduction}

Surface texturing has been widely employed to ameliorate adverse tribological conditions in various contacts [1]. These include texturing of cylinder liner surfaces in the vicinity of top piston ring reversal at the top dead centre (TDC) [2,3] or partial surface texturing of the piston ring itself [4]. Texturing has been shown to improve/palliate mixed and boundary regimes of lubrication which are predominant at piston reversals, sometimes reducing incylinder friction by as much as $2-4 \%$ [5-7]. Texturing has also been used effectively in other contact conjunctions, such as for face seals [8], thrust bearings [9] and journal bearings [10]. The underlying reason for this is the retention of pockets of lubricant as reservoirs within the formed textures. This leads to pressure perturbations within the ring-liner sliding contact, a phenomenon known as micro-hydrodynamics [11]. However, despite the accrued benefits in reducing friction, and the emerging fundamental understanding of the underlying mechanisms, optimal performance of textured patterns remains somewhat illusive. This is because of a plethora of variables, such as texture type, its distribution, geometry and in particular their positioning with respect to the inlet conjunction.

A cacophony of numerical models, parametric studies and optimisation procedures have been employed with the purpose of elucidating optimal texture parameters. The current prevailing 
approach has led to increasingly time consuming and detailed numerical analyses, providing "optimal" solutions for specific cases. In addition, issues regarding oil loss and inlet boundary starvation would play significant roles on the effectiveness of textured surfaces. Therefore, true boundary conditions for inlet lubricant availability are of importance. Birkhoff and Hays [12] determined the onset of reverse flow in the inlet conjunction of the contact as the point at which the lubricating film separates from the solid boundaries as a function of pressure gradient. Tipei [13] used potential flow analysis for vortex flow intensity to determine the stagnation point with no reverse flow thereafter, from which point laminar inward bound inlet flow may be assumed. A pressure gradient of $d p / d x=4 U \eta / h^{2}$ for a single sliding surface was determined. Flow velocity and true inlet conditions are the essential prerequisites for the understanding of the role of surface textures and their positioning within a contact domain. Therefore, a more representative analysis for flow dynamics through textured surfaces may be through use of Navier-Stokes equations. Such an approach is highlighted by Cuppilard et al [14] for surface texture features on an inclined pad slider bearing. It was noted that introducing dimples in the recirculation region only exacerbated the swirl flow, leading to reduced load carrying capacity. Shahmohamadi et al [15] extended such analyses to big-end bearings as well as to piston rings, also including thermal effects, inlet reverse flow and outlet cavitation [16, 17]. They noted complex multi-phase flow through the dimples, including regions of cavitation, which affect load carrying capacity as well as friction. Dobrica and Fillon [18] investigated the applicability of Reynolds equation to faithfully represent the flow in surface texture features. It was shown that for flows with low Reynolds number and a high texture width-to-depth ratio Reynolds equation could be used with good degree of confidence.

The approach in the current paper demonstrates how the modification of an existing geometry through surface texturing can improve tribological performance. It is shown that a relatively simple analytical solution of Reynolds equation can be used effectively to capture flow conditions in textured regions of contacts with sufficient inlet wedges, including the effect of flow recirculation. This approach enables sensitivity analysis with regard to the positioning of textures for flow optimisation. The approach precludes the formation of cavitation regions as described by Shahmohamadi $[16,17]$.

\section{Hydrodynamic Analysis}

Reynolds equation for the general case of a one-dimensional sliding contact under steady state lubricant entrainment for an iso-viscous incompressible fluid becomes:

$\frac{\partial}{\partial x}\left(h^{3} \frac{\partial p}{\partial x}\right)=6 \eta U \frac{\partial h}{\partial x}$

The pressures usually generated in fully and partially conforming contacts, such as in journal bearing and piston ring-cylinder liner contact are usually insufficient to induce piezo-viscous behaviour of the lubricant film. This is the general case considered here. This methodology is subsequently extended to the case of the piston compression ring-cylinder bore contact. Therefore, in this case no side-leakage of the thin lubricant film along the periphery of the cylinder bore is assumed. Furthermore, the one-dimensional analysis, representative of ring- 
bore contact also assumes perfect circumferential conformance (i.e. effective sealing action of the compression ring). Haddad and Tian [19] showed the validity of a one-dimensional analysis in such a case for rings with large length-to-width ratio; in excess of 30 . In practice, the compression ring is subjected to in-radial plane modal behaviour and out-of-plane twist and bending [20-22]. Furthermore, in this analysis, the bore is considered to be a right circular cylinder, which is not the case in practice due to its out-of-roundness and cylinder block thermo-elastic distortion [23]. These features are rarely taken into account in analytical as opposed to more detailed numerical solutions.

The geometry of the converging-diverging sliding contact is shown in figure 1 , where $b$ is the ring contacting face-width, $x_{s}$ is the position of commencement of the textured region, $h_{w}$ is the width of a texture feature, and $h_{d}$ and $h_{0}$ are the texture height and minimum lubricant film thickness respectively.

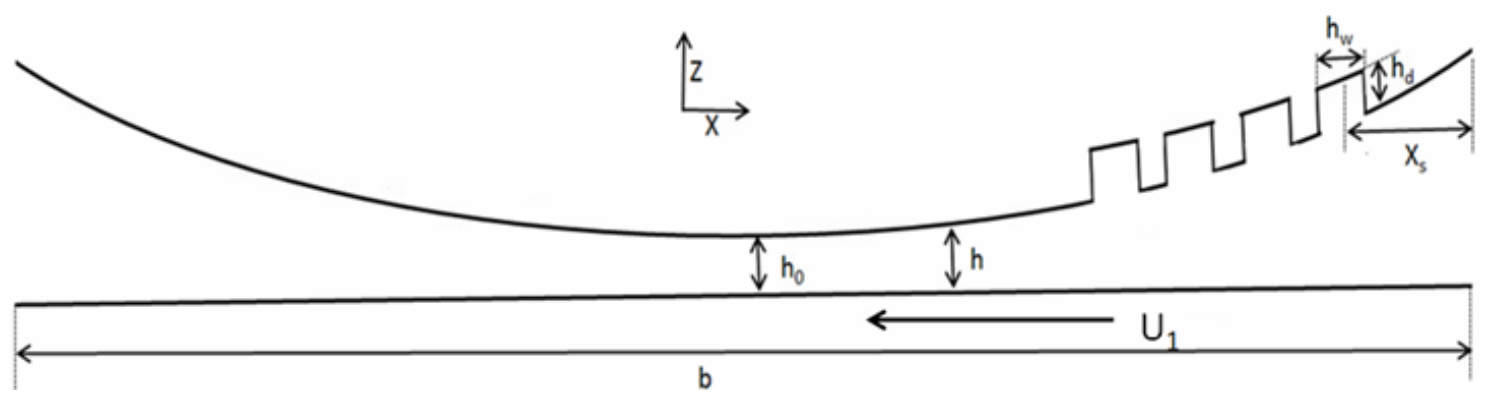

Figure 1: Geometry of bearing

The inlet boundary is considered to be fully flooded and at ambient pressure, thus:

$p=p_{a}$ at $x=x_{i n}$

The exit boundary used is the commonly employed Swift [24] - Stieber [25] conditions:

$\frac{d p}{d x}=0$ and $p=p_{c a v}$ at $x=x_{c a v}$

The cross film velocity distribution can be determined at any position along the conjunctional length using the implicit assumptions that the Poiseuille flow has a parabolic distribution across the film and the Couette flow velocity is characterised by a linear distribution [26], thus:

$u(x, z)=\frac{1}{2 \eta}\left(\frac{d p}{d x}\right) z(h-z)+\frac{z}{h}\left(U_{2}-U_{1}\right)+U_{1}$

The resulting velocity profile at any position is the summation of the Poiseuille and Couette induced flows. The velocity distributions of particular interest in the converging section of the flow are shown in figure 2(b). 


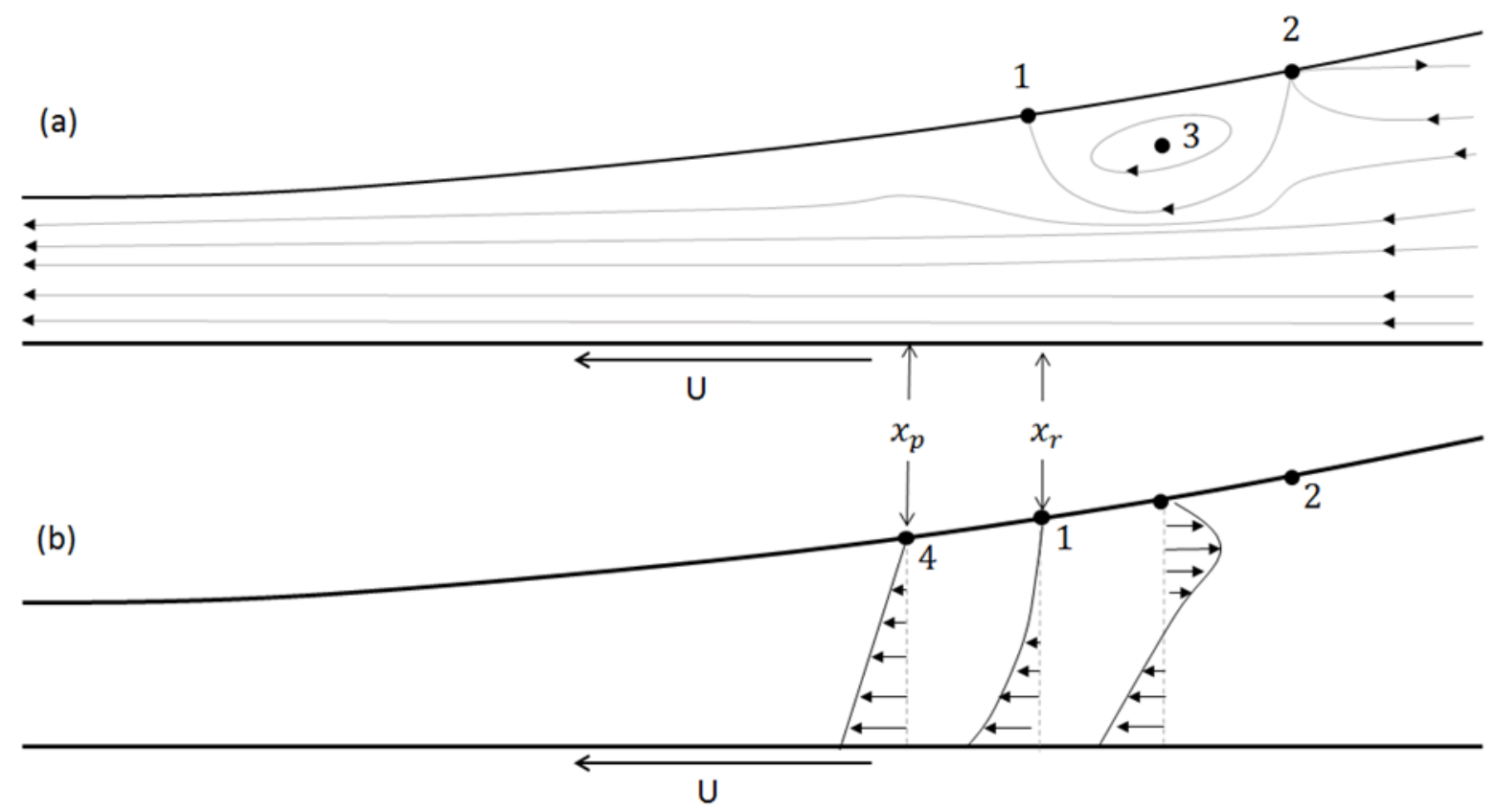

Figure 2: (a) Conjunctional inlet flow, (b) Cross film velocity distribution

At point 1 , the recirculation shown at the entrance to the contact has ceased with no further swirl flow component [12]. Birkhoff and Hays [12] determined the onset of recirculation as the separation exit boundary condition. In the case of a slider bearing, the Prandtl-Hopkins separation condition and that determined by Birkhoff and Hays [12] are congruent. The pressure gradient calculated by Birkhoff and Hays [12] in the inlet region determines the point at which flow recirculation terminates. At this point the relative velocity gradient stagnates at the sliding wall and can be stated as:

$x=x_{r} ; \frac{d u}{d z}=0$ at $z=h ; \frac{d p}{d x}=2 U \eta / h^{2}$

Downstream of the stagnation point the flow acts in a truly laminar fashion. Mathematically this represents the maximum pressure gradient.

At point 4 in figure 2(b) the maximum pressure is reached and is characterised by pure Couette flow as the pressure derivative vanishes momentarily and thereafter reverses in direction towards the contact exit [27]:

$x=x_{p}, p=p_{\max }$ when $\frac{d p}{d x}=0$

Eventually, the lubricant film ruptures at the cavitation boundary; $x_{c a v}$.

The pressure differential is influenced by the film geometry. Therefore, several different ring profiles are considered in the current study. The converging-diverging geometry is determined by:

$s(x)=\frac{h_{c} x^{n}}{(b / 2)^{2}}$ 
and the effective radius of curvature is: $R=\frac{b^{2}}{8 h_{c}}$.

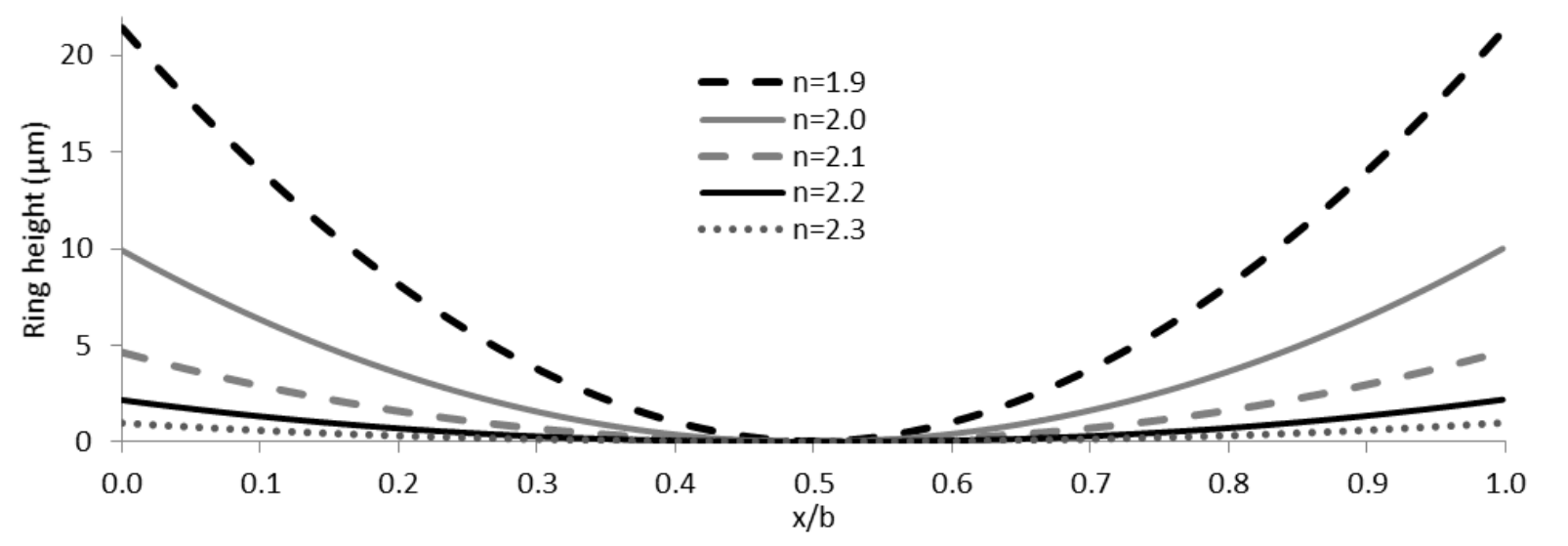

Figure 3: Various ring face profiles

\section{Results for generic sliding contact}

Initially shallow textures are used so as to allow the overall slider geometry to govern the recirculation point without any significant interference from the geometry of the texture features. These textures have a width-to-height ratio of 50. This ratio allows for Reynolds equation to accurately predict the effect of surface texturing [18]. To allow for a fine resolution of texture placement, two textures covering $x_{T}=12 \mu \mathrm{m}$ of a region of the ring are employed (Figure 1). This approach allows for the removal of several variables, focussing on gaining an understanding of the effect of texture positioning. Other important variables such as texture shape and density are outside the scope of the current study, but are quite important.

The data in table 1 is chosen such that Reynolds equation is applicable for modelling lubricant flow within textures. The Reynolds number never exceeds $R e=\frac{\rho U h}{\eta}<0.25$ which is shown to be a suitable texture width-to-height ratio [18].

Table 1: Input data for the initial case study

\begin{tabular}{|l|l|c|}
\hline Minimum film thickness $\left(h_{0}\right)$ & 1 & $\mu m$ \\
\hline Viscosity $(\eta)$ & 0.1 & Pa.s \\
\hline Speed & 0.1 & $m / s$ \\
\hline Dimple ratio $\left(h_{\mathrm{w}} / h_{\mathrm{d}}\right)$ & 50 & - \\
\hline
\end{tabular}

A variety of ring face profiles (figure 3) are used to alter the pressure gradient and the point at which inlet lubricant recirculation (i.e. $x_{r}$ ) ceases. 


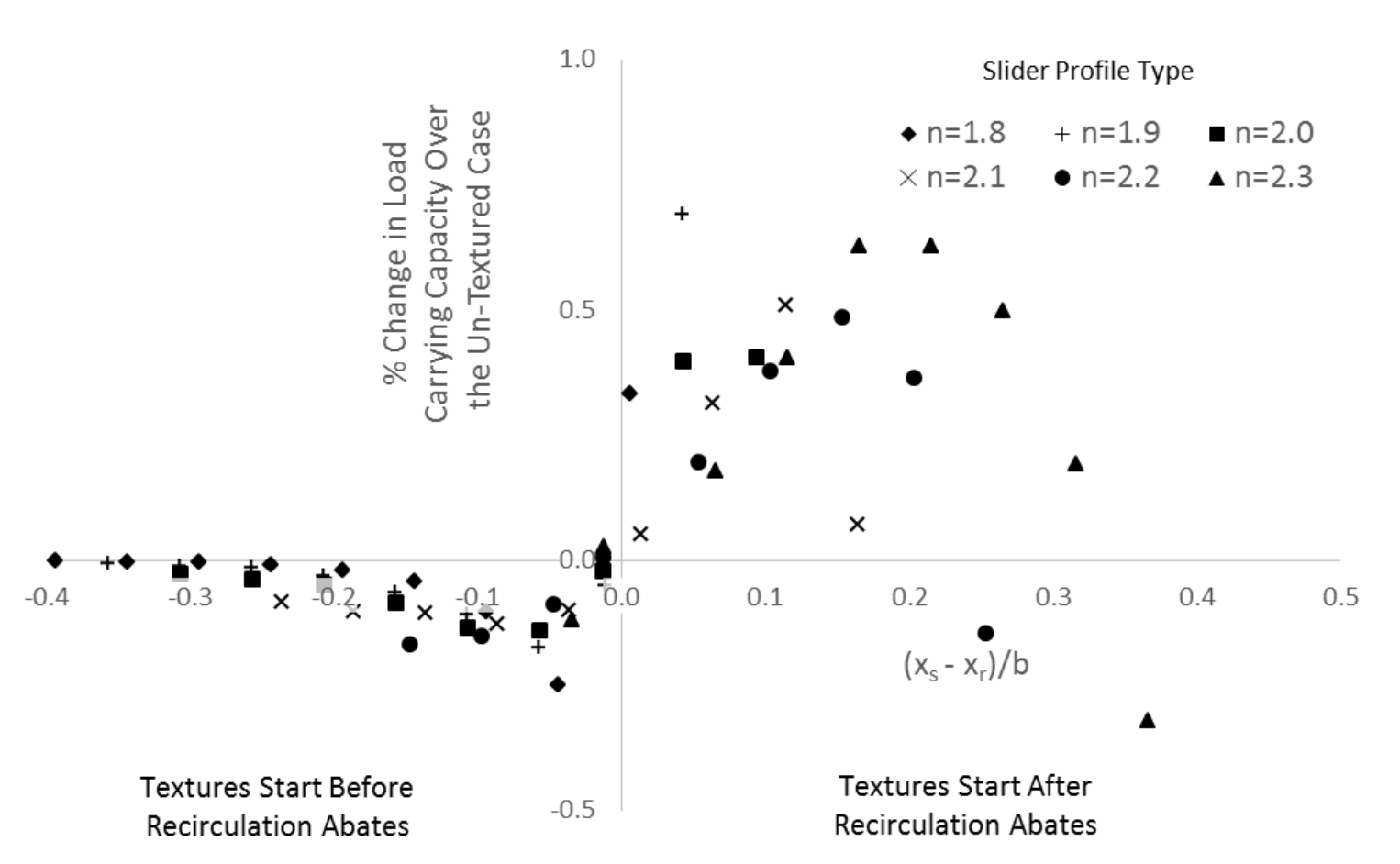

Figure 4: Percentage change in load carrying capacity with texture start position away from the flow recirculation point (for various ring shapes)

Figure 4 shows the relationship between the texture position and the effect of recirculation on the load carrying capacity for the various ring face geometries. The comparison is made between the un-textured and textured surfaces in each case. The abscissa of the graph is the relative position of the start of the textured region with respect to the recirculation boundary (i.e. $x_{s}-x_{r}$ ). This distance is normalised with respect to the ring face-width, $b$. Therefore, the measure used is the normalised relative texture position with respect to the recirculation point (i.e. $\frac{x_{S}-x_{r}}{b}$ ). It is hypothesised that flow into the textures would be affected by recirculation and back-flow if the textures are introduced prior to or within the recirculation region. This would affect the effective pressure perturbations, usually induced by the textures as described in [11]. It is clear that in the cases where the abscissa value is negative, in fact a loss in load carrying capacity with respect to the equivalent un-textured ring surface of the same geometry is observed. For positive values of $\frac{x_{s}-x_{r}}{b}$ (i.e. textures position post recirculation boundary, figure 2(a)) an improvement in load carrying capacity is attained. 


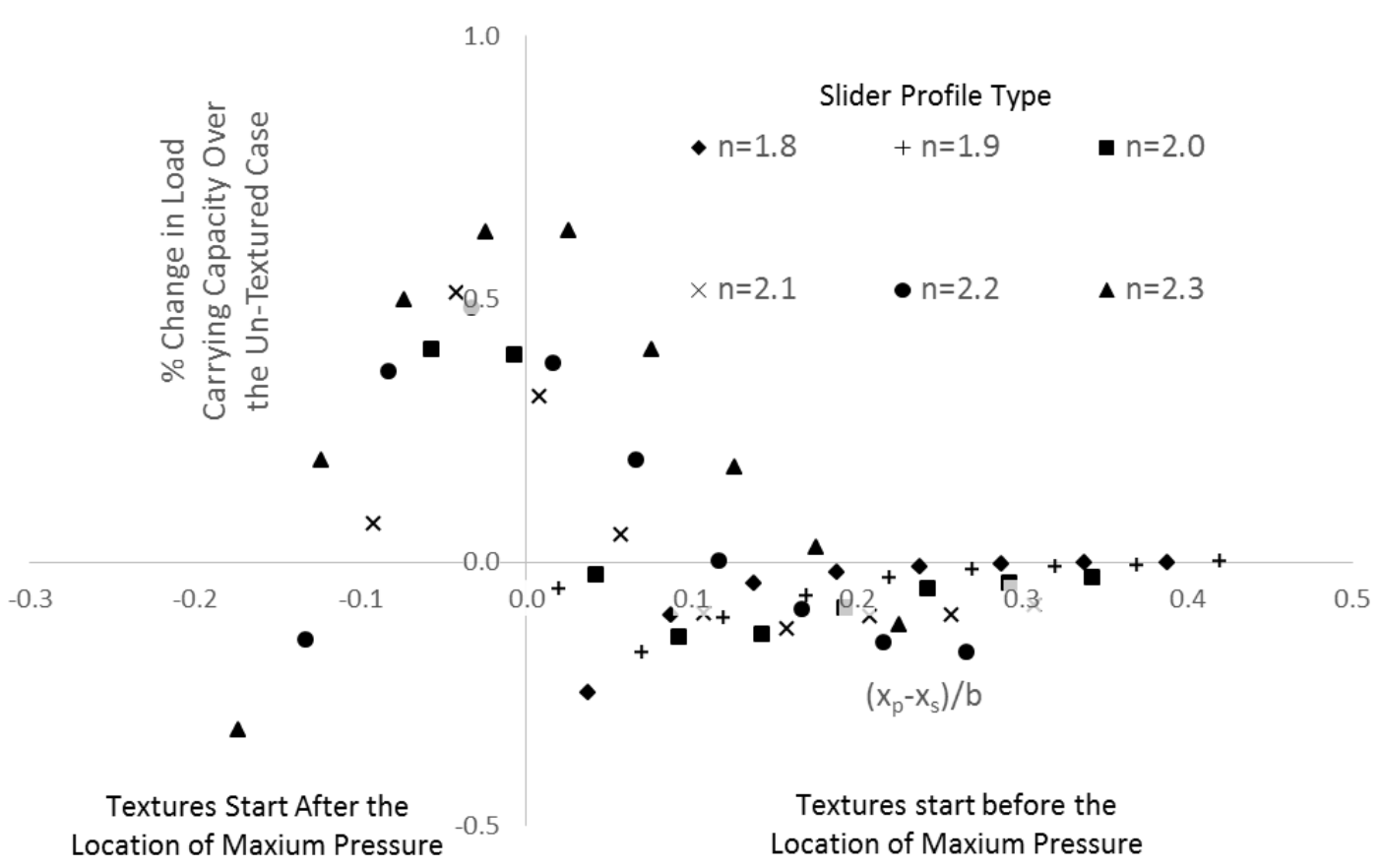

Figure 5: Variations in load carry capacity with start of texturing at a distance from

the point of maximum pressure

Furthermore, figure 5 shows that when the surface texture features are introduced just prior to the point of maximum pressure, based on the relative position of the start of textured region with respect to the point of maximum pressure, a greater improvement in the load carrying capacity is noted. The abscissa in this figure is the normalised relative texture position with respect to the position of maximum pressure (i.e. $\frac{x_{p}-x_{s}}{b}$ ). The position of maximum pressure used in this case is that obtained for the un-textured equivalent cases. It is noteworthy that both the end of the recirculation region (recirculation boundary) and the maximum pressure position are when: $\frac{d p}{d x}=0$, where the lubricant flow is predominantly Couette. Therefore, any pressure perturbations are only governed by the textures themselves. 


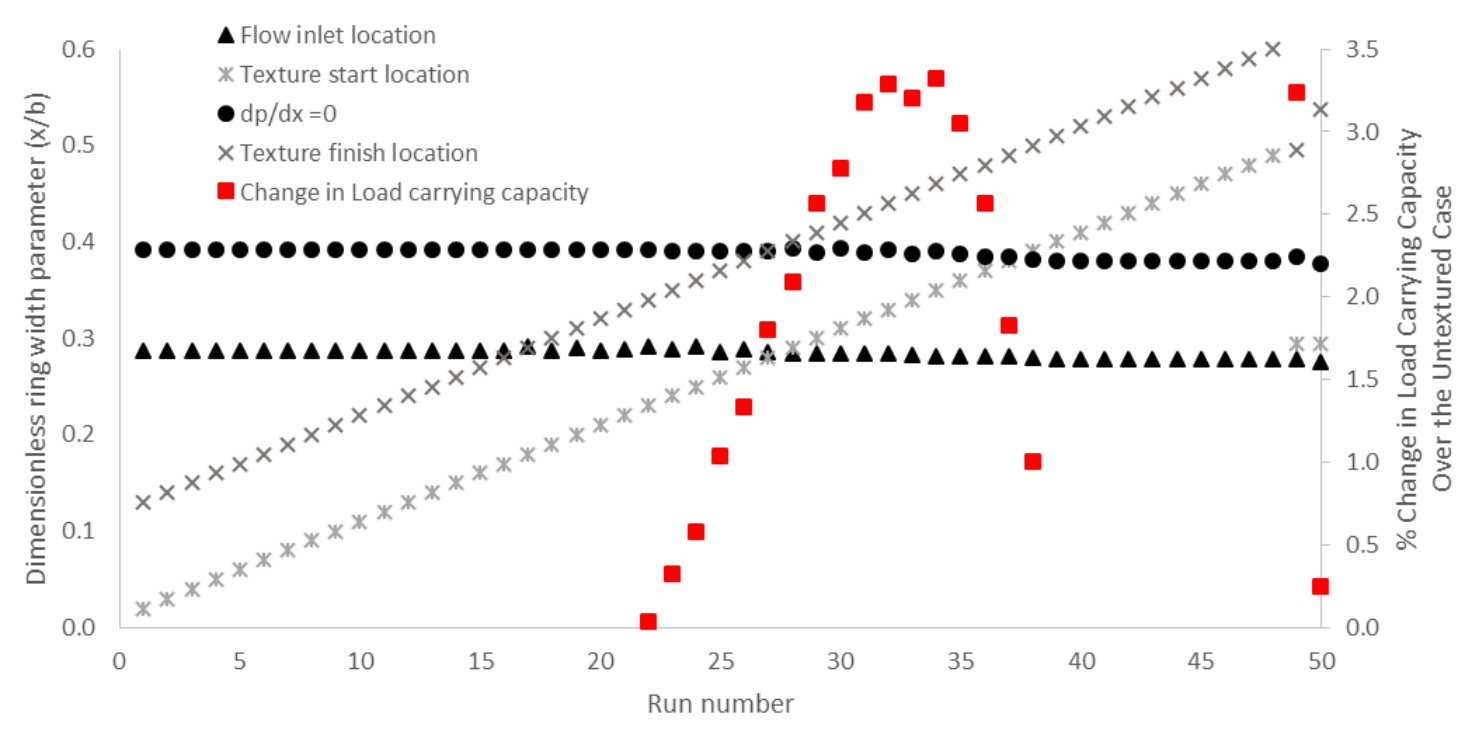

Figure 6: Change in Load carrying capacity for various texture positions

Therefore, the optimum region for texturing is between the end of the recirculation region and prior to the maximum pressure position (i.e. in the laminar Couette flow region). This is clearly shown by the improved load carrying capacity in figure 6 for the cases where the textured region appears between these stated boundaries.

A better understanding can be gained through simple flow analysis. For incompressible volumetric flow:

$$
Q=-\frac{h^{3}}{12 \eta} \frac{d p}{d x}+\frac{U h}{2}
$$

The effect of a surface texture features on the lubricant flow rate in equation (8) would increase the local film thickness $h(x)$ and possibly the pressure gradient $d p / d x$ due to microhydrodynamic action. As volumetric flow through the bearing is conserved any restriction would partially starve the contact (neglecting any side-leakage). A textured feature could act as a flow restrictor under certain conditions. For example, texture-induced pressure perturbations introduced in the region of maximum pressure gradient for the equivalent smooth surface geometry can result in diminished lubricant entrainment. The maximal value of pressure gradient is given by $\frac{d p}{d x}=2 U \eta / h^{2}$. This gradient also corresponds to the onset of flow reversal. Upstream of this position shallow textures cannot create any restriction in flow greater than that determined by the bearing's overall geometry. In this case the textureinduced pressure perturbations and build-up add to the load carrying capacity, but do not significantly change the flow rate through the contact. The converse is true of any textureinduced perturbations down stream of maximum pressure region. This simple analysis is confirmed by the results in figure 6 . 


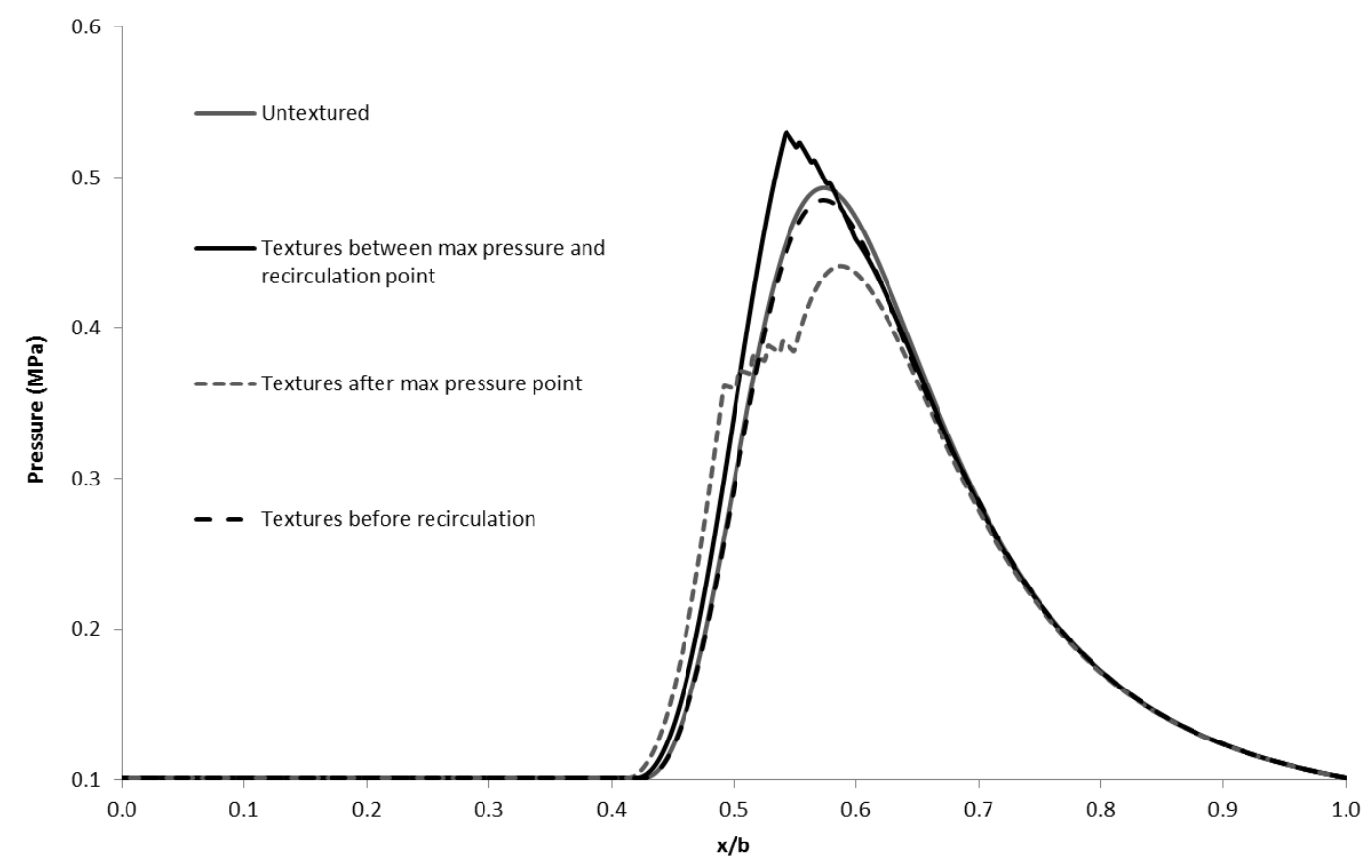

Figure 7: Pressure distribution Ring profile $n=2$ different texture positions

The effect of texture-induced pressure perturbations, responsible for the improved load carrying capacity is shown in figure 7 . It can be seen that pressure perturbations alone are not the underlying mechanism for improved conditions, but together with the location of the textured region. This is clear in the pressure distributions of figure 7 related to the points marked in figure 6 .

\section{Piston compression ring conjunction}

The methodology outlined above is applied to the case of piston compression ring of a single cylinder normally aspirated 4-stroke high performance motocross motorbike engine. The contact of compression ring to cylinder liner is subjected to transient lubrication condition on account of variations in contact load (resulting from combustion pressure) and contact kinematics (variable sliding speed including reversals). In this case, retaining the same assumptions as the aforementioned general case (equation (1)), but taking into account the transient nature of the prevailing conditions, the appropriate form of Reynolds equation becomes:

$\frac{\partial}{\partial x}\left(\frac{h}{12 \eta_{e}} \frac{\partial p}{\partial x}\right)=\frac{U_{1}+U_{2}}{2} \frac{\partial h}{\partial x}+\frac{\partial h}{\partial t}$

More comprehensive solutions, including 2-dimesional analysis with thermal effects, sideleakage flow and surface roughness are provided elsewhere [3, 11, 28, 29]. 
Various studies have shown that the generated pressures are insufficient to cause any appreciable localised deformation of the contiguous surfaces, thus the lubricant film thickness can be stated as [30-32]:

$h(x, t)=h_{o}(t)+s(x)+h_{t}(x)$

where, $h_{o}(t)$ is the minimum film thickness which is a function of time, $s(x)$ is the profile of the ring contact face and $h_{t}(x)$ is the depth of the texture. The asymmetric measured ring profile and the chosen texture geometry are shown figure 8 . The region to be textured is selected by reviewing the recirculation point and maximum pressure point for the un-textured piston ring results. A texture width of $20 \mu \mathrm{m}$ is selected as it is a typical spot size for a variety of lasers. The combination of these two parameters while allowing for a small gap between them, gives the number of textures in each region. The high texture density has been shown to be advantageous by Etsion et al [33] who has thoroughly investigated the influence of texture density and various other properties. The texture depth was chosen so that recirculation internal to the texture is prohibited. Textures of similar geometry to that described below can be produced using femtosecond laser technology [34].

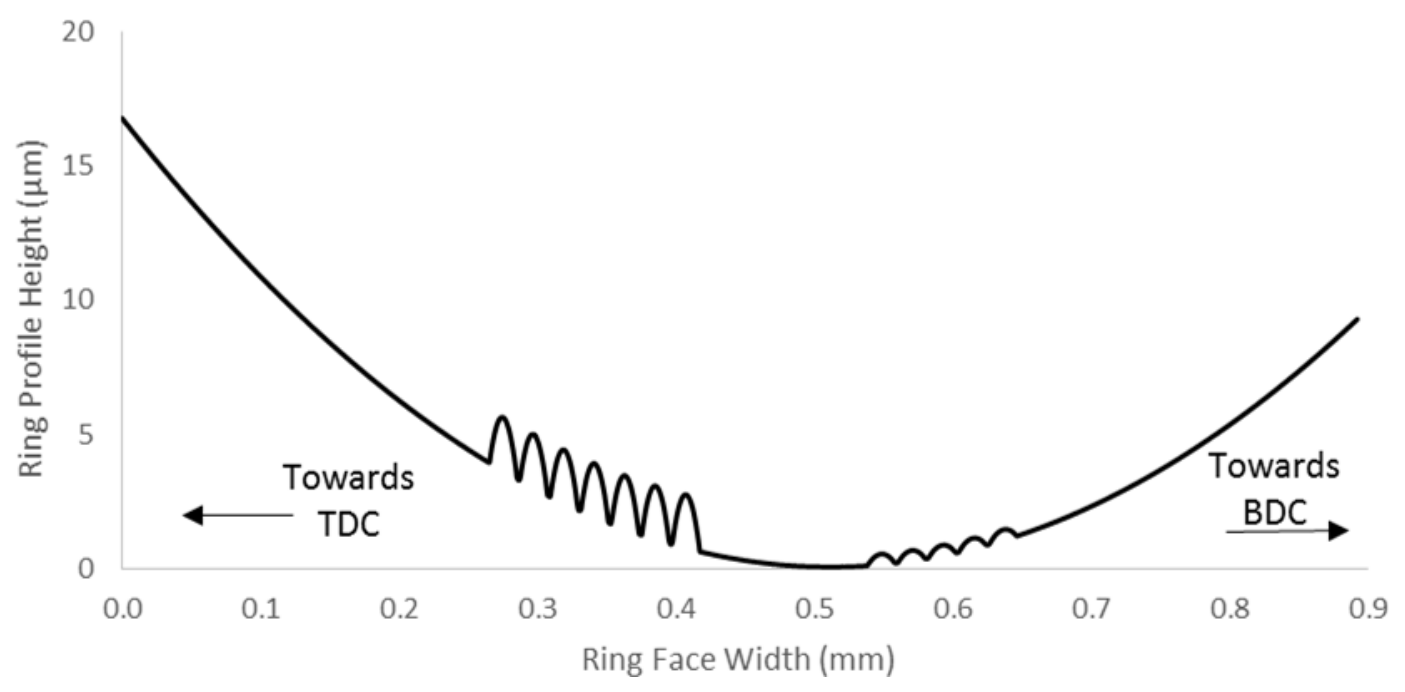

Figure 8: Textured ring profile geometry

The in-cylinder gas pressure and the ring sliding velocity used in the current study are shown in figure 9. The other geometrical, material and surface topographical parameters are listed in tables 2 and 3. 


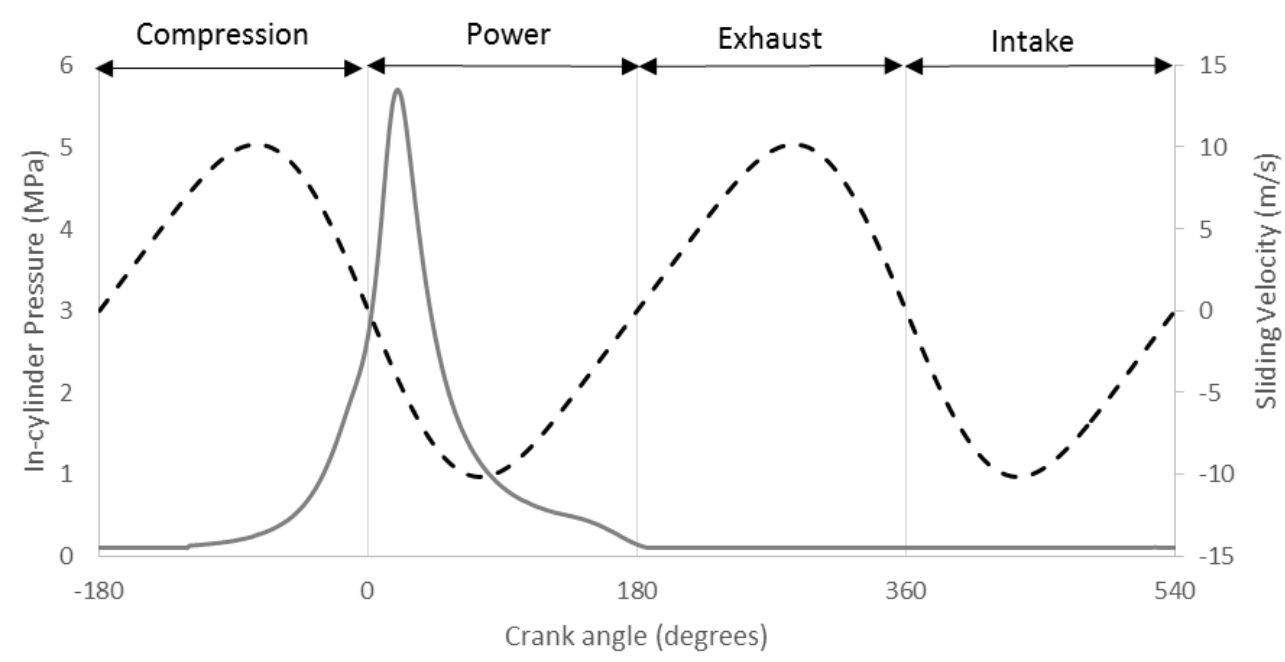

Figure 9: In-cylinder pressure and piston velocity

Table 2: Engine data

\begin{tabular}{|l|l|c|}
\hline Parameter & Value & Unit \\
\hline Crank-Pin radius & 31.5 & $\mathrm{~mm}$ \\
\hline Connecting rod length & 107 & $\mathrm{~mm}$ \\
\hline Bore nominal radius & 48 & $\mathrm{~mm}$ \\
\hline $\begin{array}{l}\text { Lubricant Kinematic } \\
\text { viscosity @ } 100{ }^{\circ} \mathrm{C}\end{array}$ & 11.99 & $\mathrm{GPa}$ \\
\hline Young's modulus for Liner & 75 & - \\
\hline Liner Poisson's ratio & 0.3 & $\mathrm{GPa}$ \\
\hline $\begin{array}{l}\text { Young's modulus for ring } \\
\text { coating material }\end{array}$ & 203 & - \\
\hline Ring's Poisson's ratio & 0.3 & $\mu \mathrm{m}$ \\
\hline Composite RMS roughness & 0.87 & \multicolumn{2}{|c|}{} \\
\hline
\end{tabular}

Table 3: Texture data

\begin{tabular}{|l|l|c|}
\hline Parameter & Value & Unit \\
\hline Texture width & 20 & $\mu \mathrm{m}$ \\
\hline Texture depth & 1.7 and 0.5 & $\mu \mathrm{m}$ \\
\hline Distance from edge & 0.267 and 0.240 & $\mathrm{~mm}$ \\
\hline Shape & Parabolic & - \\
\hline Dimple spacing & 2 & $\mu \mathrm{m}$ \\
\hline
\end{tabular}

\section{Friction}

Prediction of frictional power loss is a prelude to any palliative action to mitigate or reduce the same, including introduction of textured surfaces. Generated friction is as the result of 
viscous shear of a thin lubricant film as well as direct contact of rough surfaces through interaction of asperities on the opposing surfaces.

Viscous friction is obtained as:

$f_{v}=l \int_{-\frac{b}{2}}^{\frac{x_{b}}{2}}\left| \pm \frac{h}{2}\left(\frac{d p}{d x}\right)-\frac{\eta_{e} \Delta U}{h}\right| d x$

where, $l=2 \pi r_{0}$.

At or in the vicinity of ring reversals at the top and bottom dead centres, the lubricant film can no longer fully support the applied contact load and therefore some degree of boundary interaction occurs. It is assumed that boundary friction comprises two contributions. One is due to adhesion of opposing asperities into junctures which are continually broken with the continuance of relative sliding motion. If the pressure-induced shear strength of asperities is $\zeta$, then the adhesive contribution is obtained as: $\zeta W_{a}$, where $W_{a}$ is the share of contact load carried by the direct contact of the rough surface topography. For the formed ferrous surface oxide layer $\zeta=0.17$ [35].

The second contribution to boundary friction is due to a thin adsorbed film of lubricant entrapped between the interspatial cavities of asperities. Briscoe and Evans [36] proposed that such diminutive films act in non-Newtonian shear, subjected to the limiting Eyring shear stress, $\tau_{0}$. This frictional contribution takes the form: $\tau_{0} A_{a}$, where $A_{a}$ is the total area of asperity summits which come into contact, and $\tau_{0}=2 \mathrm{MPa}$ for the engine oil used in the current study. Hence, boundary friction is obtained as:

$f_{b}=\tau_{0} A_{a}+\varsigma W_{a}$

The asperity contact area and their share of carried load is found by assuming the uppermost region of the surfaces, where direct surface interaction is likely conform to a Gaussian distribution of asperities heights [37].

$A_{a}=\pi^{2}(\zeta \kappa \sigma)^{2} A F_{2}(\lambda)$

$W_{a}=\frac{8 \sqrt{2}}{15} \pi(\zeta \kappa \sigma)^{2} \sqrt{\frac{\sigma}{\kappa}} E^{\prime} A F_{5 / 2}(\lambda)$

where, $F_{2}(\lambda)$ and $F_{5 / 2}(\lambda)$ are statistical functions relating the probability of interacting opposing asperities as functions of the Stribeck's oil film parameter: $\lambda=\frac{h}{\sigma}$, where $\sigma$ is the composite root mean square roughness of the counter face surfaces [37]. A similar approach was made by Akalin and Newaz [38] as well as by Gore et al [39], both of which closely approximated the measured frictional losses at the compression ring-cylinder liner conjunction. The topography of cross-hatch honed surface of cylinder liners is non-Gaussian which should ideally be represented by specifically measured statistical distribution of surface peak heights as recently shown by Leighton et al [40]. 
Finally, the total conjunctional frictional and power loss becomes:

$f=f_{v}+f_{b}$

And, the frictional power loss is:

$P_{f}=f|U|$

\section{Method of Solution}

The load carrying capacity of the contact is obtained as a combination of the load carried by the direct interaction of asperities on the opposing surface, $W_{a}$ (equation (14)) and the lubricant reaction:

$W_{h}=\int p d A_{h}$

The carried load must equate the applied conjunctional load as the result of ring tension and combustion gas pressure acting behind the inner rim of the ring, both of which strive to adhere the ring to the cylinder liner surface, $F[3,11,23]$. Therefore, the following convergence criterion should be met:

$\left|\frac{W_{h}+W_{a}-F}{F}\right| \leq \varepsilon$

If this criterion remains unfulfilled, an iterative solution is pursued by changing the instantaneous minimum clearance, $h_{0}$. When the convergence criterion is met the crankangle $\varphi$ is advanced, the new sliding velocity of the ring is obtained and the entire calculation procedure is repeated. The analysis is carried out for several engine cycles (engine cycle: $-180 \leq \varphi \leq 540^{\circ}$ ).

\section{Results and Discussion}

Etsion and Sher [3] reported a significant reduction of up to $4 \%$ in fuel consumption with measurement repeatability of $\pm 0.5 \%$ using a partially etched piston compression ring. This was very similar to that reported in $[2,6]$, where the surface of cylinder liner in a high performance engine was etched at the piston top dead centre (TDC) reversal. Therefore, two approaches have been followed; one to provide texturing on the sliding surface, whilst the other employs texturing on the stationary counter face. The philosophy behind the latter approach is that most of the frictional losses occur at the TDC in transition from the compression to the power stroke in a 4-stroke engine. This is mainly due to the increased incidence of boundary interactions as shown by the direct measurement of in-cylinder friction for both motored and fired engines by Gore et al [41], using a suitably instrumented floating 
liner arrangement. Styles et al [42] showed that the frictional power loss in this part of the piston cycle can be as much as $30-40 \%$ of the entire cyclic losses. Elsewhere in the engine cycle, with predominance of hydrodynamic regime of lubrication and assuming a fully flooded inlet, the introduction of textures enhances the lubricant film thickness which can also lead to increased oil loss. Yet, as Etsion [7] has noted the overall gains with both methods are remarkably similar. The underlying mechanism, fundamentally described in this paper, provides a suitable explanation for the success of partial texturing on the compression ring itself. It shows that positioning of the textures on the ring with respect to the position of maximum pressure and inlet recirculation boundary, both functions of ring contact face profile, is a critical factor. The results in figure 10 confirm this for the case studied here. An overall energy saving of $3.9 \%$ is obtained for the textured ring with respect to an un-textured equivalent. The figure shows that with the partially textured ring an improvement is observed (positive \% change) for most of the cycle, but not everywhere. The net gain is $3.9 \%$, and it is clear that most gain occurs during the power stroke in this case. The ring profile in this case is parabolic with a ring contact face-width of $0.8 \mathrm{~mm}$. Etsion and Sher [3] reported similar findings for a thicker ring of broader face-width. Nevertheless, the results of both studies show remarkable agreement.

Figure 11 (a), together with the result in figure 10, shows that significant gains occur when the textured region falls in-between the end of lubricant recirculation region and the position of the maximum pressure, both of which alter in a transient manner according to the instantaneous conditions. The corresponding predicted film thickness and total generated friction (viscous and boundary) are shown in figure 11(b), further confirming the foregoing discussions.

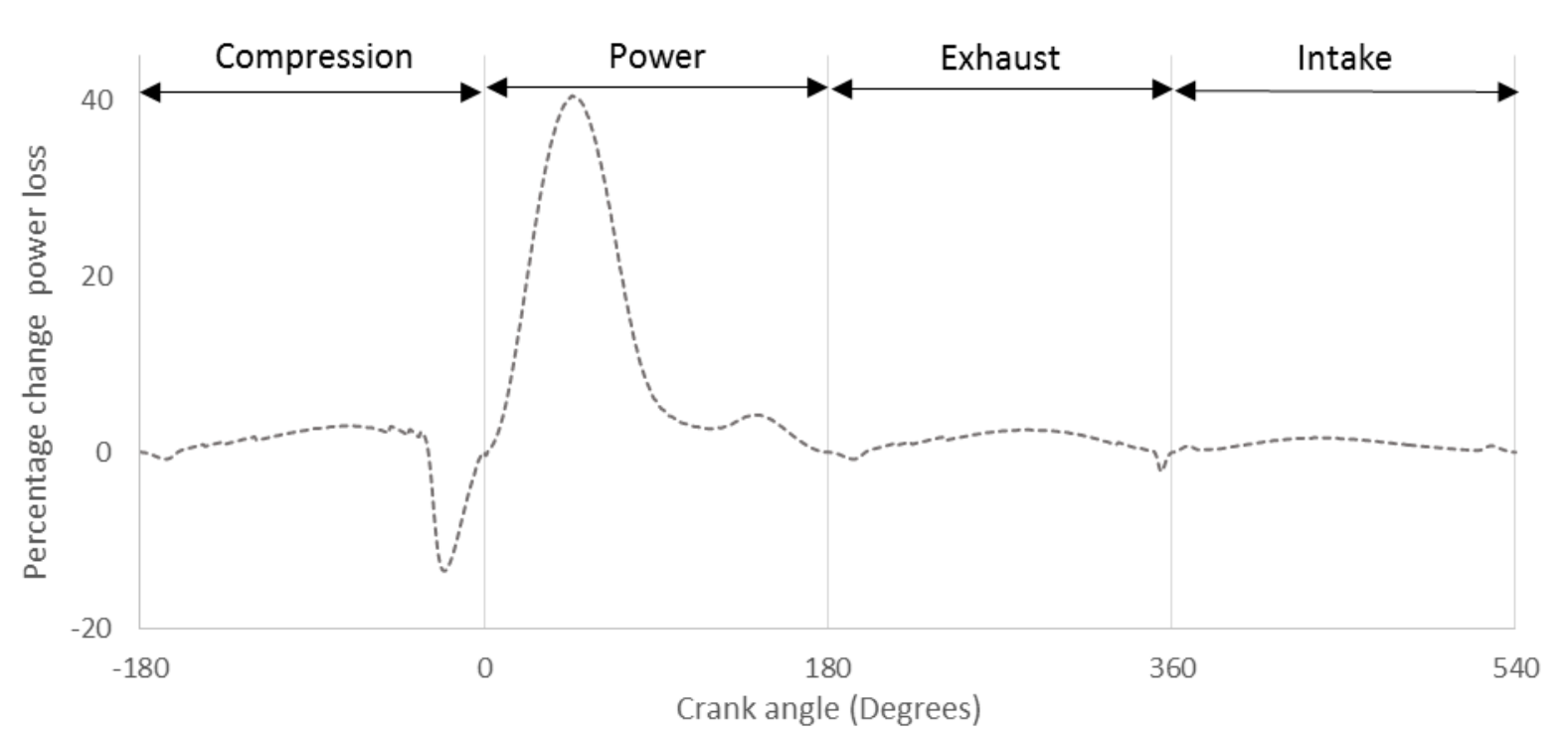

Figure 10: Percentage change in power loss for a textured ring with respect to the un-textured (a)- Transience in position of textured region 


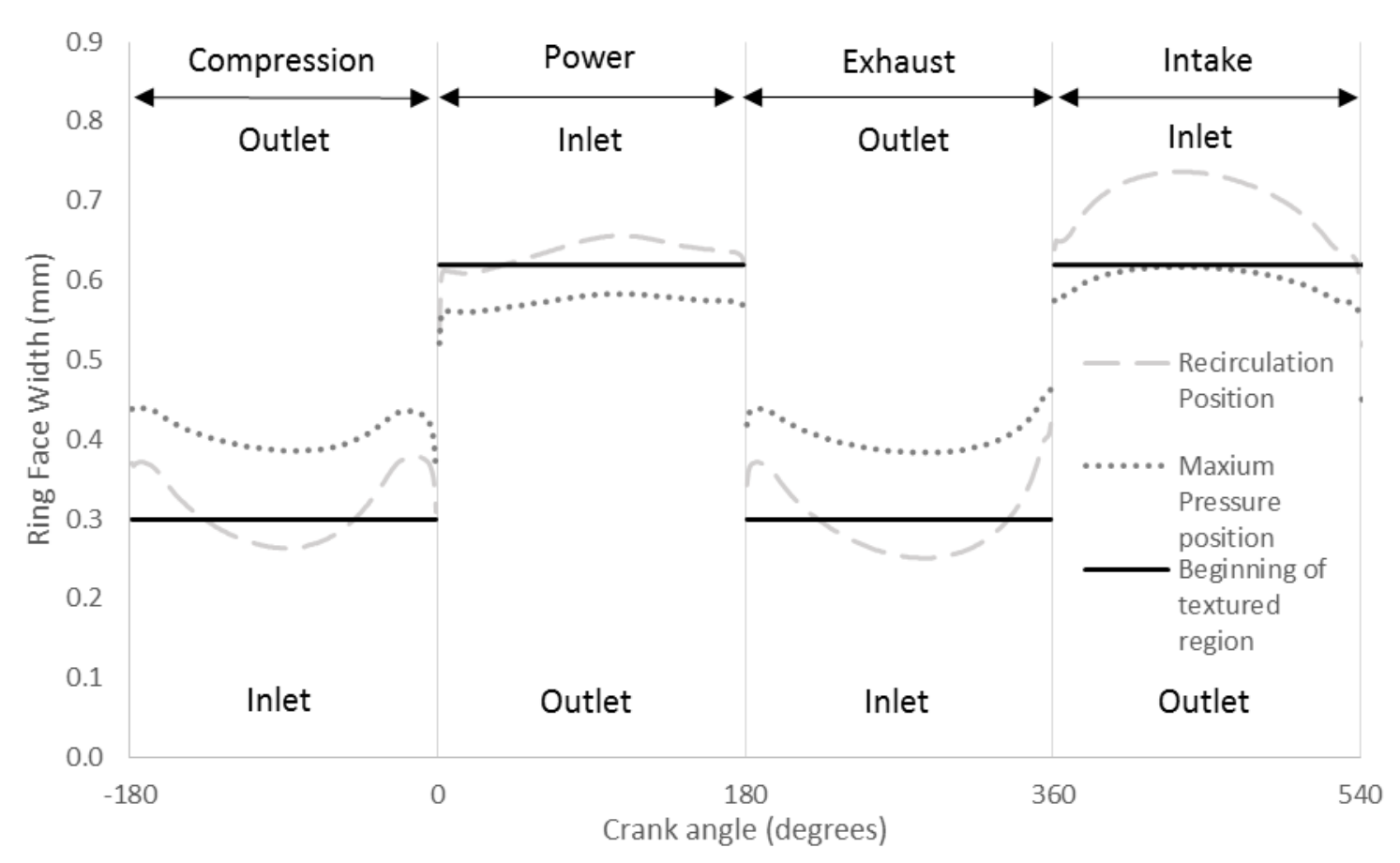

(b)- Cyclic film thickness and friction change with texturing

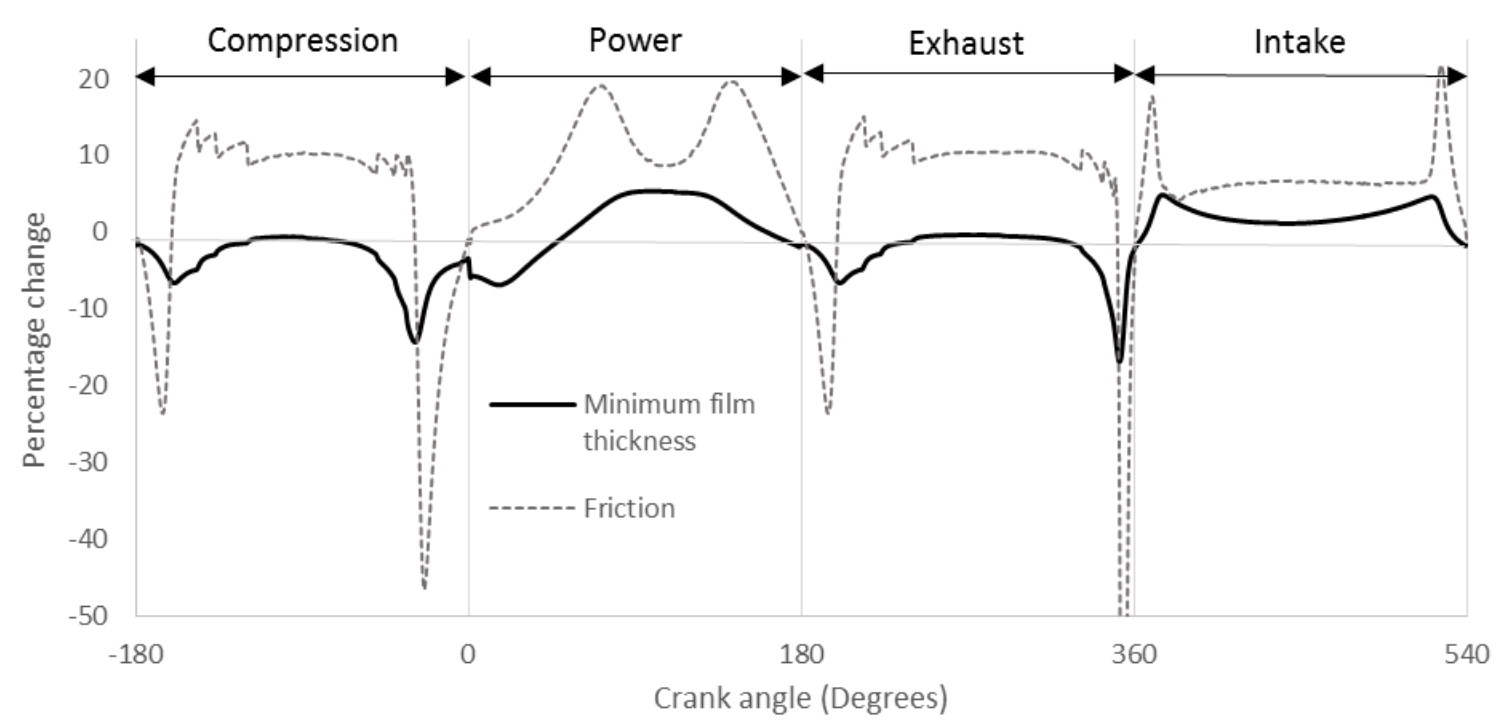

Figure 11: Transient changes in film thickness and friction with a textured ring with respect to the un- textured

\section{Conclusions}

A time efficient analytical method is presented to determine and optimise the position of textured features in partial texturing of a parabolic thin compression ring of high performance motocross motorbike race engines. The method is generic and would be suitable for many texture types. The results are demonstrated for a parabolic ring face profile with shallow dimples which can be incorporated through laser surface texturing. 
It is shown that performance of surface textures is significantly dependent on their induced pressure perturbation, but not exclusively so. A further requirement is to create the textures downstream of the entrained lubricant recirculation boundary as this would disrupt any micro-hydrodynamic lift. Downstream of recirculation there is predominance of Couette flow into the contact proper. For the same reasons a region with a rising pressure gradient would be beneficial, so the textures should reside upstream of the contact peak pressure.

\section{Acknowledgement of Funding:}

The authors are grateful to the Engineering and Physical Sciences (EPSRC) for funding of the Encyclopaedic Program grant, which constituted part-funding of this research.

\section{Nomenclature}

\begin{tabular}{|c|c|}
\hline$A_{a}$ & Real asperity contact area \\
\hline$A_{h}$ & Hydrodynamic area \\
\hline$b$ & Ring face-width \\
\hline$E^{\prime}$ & Reduced elastic modulus \\
\hline$f$ & Total friction \\
\hline$f_{b}$ & Boundary friction \\
\hline$f_{v}$ & Viscous friction \\
\hline$F$ & Ring load \\
\hline$F_{2}, F_{5 / 2}$ & Statistical functions \\
\hline$h$ & Film thickness \\
\hline$h_{c}$ & Ring crown height \\
\hline$h_{d}$ & Texture depth \\
\hline$h_{w}$ & Texture width \\
\hline$h_{0}$ & Minimum film thickness \\
\hline$l$ & Ring outer perimeter \\
\hline$p$ & Pressure \\
\hline$p_{a}$ & Atmospheric pressure \\
\hline$p_{c a v}$ & Cavitation pressure \\
\hline$p_{f}$ & Frictional power loss \\
\hline
\end{tabular}




\begin{tabular}{|c|c|}
\hline$p_{\max }$ & Maximum contact pressure \\
\hline$Q$ & Volumetric flow rate \\
\hline$u$ & Cross film velocity distribution \\
\hline$U$ & Relative sliding speed between the surfaces \\
\hline$U_{1}, U_{2}$ & Surface velocities \\
\hline$U_{2}$ & Relative sliding speed between the surfaces \\
\hline$r_{0}$ & Bore radius \\
\hline$R$ & Ring face radius of curvature \\
\hline$s$ & Ring profile \\
\hline$t$ & Time \\
\hline$W_{a}$ & Asperity load carrying capacity \\
\hline$W_{h}$ & Hydrodnamic load carrying capacity \\
\hline$x_{c a v}$ & Film rupture boundary position \\
\hline$x_{i n}$ & Inlet position \\
\hline$x_{p}$ & Position of maximum pressure \\
\hline$x_{r}$ & Recirculation termination position \\
\hline$x_{s}$ & Texture start position \\
\hline$x$ & Direction of entraining motion \\
\hline$z$ & Into the depth of lubricant film \\
\hline$\varepsilon$ & Convergence criterion \\
\hline$\eta$ & Dynamic viscosity \\
\hline$\zeta$ & Peak density \\
\hline$\kappa$ & Asperity radius of curvature \\
\hline$\lambda$ & Stribeck oil film parameter \\
\hline$\sigma$ & RMS roughness parameter \\
\hline$\tau_{\delta}$ & Eyring shear stress \\
\hline
\end{tabular}




\section{Abbreviations}

$\begin{array}{ll}\text { BDC } & \text { Bottom dead centre } \\ \text { RMS } & \text { Root mean squared } \\ \text { TDC } & \text { Top dead centre }\end{array}$

\section{References}

[1]- Etsion, I.,'State of the art in laser surface texturing", Trans. ASME, J. Tribology, 127(1), 2005, pp. 248-253.

[2]- Rahnejat, H., Balakrishnan, S., King, P.D. and Howell-Smith, S., "In-cylinder friction reduction using a surface finish optimization technique", Proc. IMechE, Part D: J. Automobile Eng., 220(9), 2006, pp. 1309-1318.

[3]- Morris, N., Rahmani, R., Rahnejat, H., King, P.D. and Howell-Smith, S., “A Numerical Model to Study the Role of Surface Textures at Top Dead Center Reversal in the Piston Ring to Cylinder Liner Contact", Trans ASME，J. Tribology, 138(2), 2016, 021703

[4]- Ryk, G. and Etsion, I., "Testing piston rings with partial laser surface texturing for friction reduction", Wear, 261(7), 2006, pp. 792-796.

[5]- Etsion, I. and Sher, E., "Improving fuel efficiency with laser surface textured piston rings", Tribology Int., 42(4), 2009, pp. 542-547

[6]- Dwyer-Joyce, R.S., Green, D.A., Balakrishnan, S., Harper, P., Lewis, R., Howell-Smith, S.J., King, P.D. and Rahnejat, H., "The measurement of liner-piston skirt oil film thickness by an ultrasonic means", SAE Technical Paper 2006-01-0648, 2006

[7]- Etsion, I., "Surface texturing for in-cylinder friction reduction", Woodhead Publishing Ltd, New Delhi (India), 2010

[8]- Etsion, I. and Halperin, G., “A Laser Surface Textured Hydrostatic Mechanical Seal”, Tribology Trans., 45(3), 2002, pp. 430-434

[9]- Brizmer, V., Kligerman, Y. and Etsion, I., "A laser surface textured parallel thrust bearing”, Tribology Trans., 46(3), 2003, pp. 397-403.

[10]- Morris, N.J., Rahnejat, H. and Rahmani, R., "Tribology of partial pad journal bearings with textured surface", IN: Proceedings of the 3rd European Conference on Tribology (ECOTRIB), Vienna, Austria, 7-9, 2011, 6pp.

[11]- Morris, N., Leighton, M., De la Cruz, M., Rahmani, R., Rahnejat, H., Howell-Smith, S., "Combined numerical and experimental investigation of the micro-hydrodynamics of chevron-based textured patterns influencing conjunctional friction of sliding contacts", Proc. IMechE, Part J: J. Eng. Tribology, 229(4), 2015, pp. 316-335 
[12]- Birkhoff, G. and Hays, D. F., "Free boundaries in partial lubrication", .J. Mathematics and Physics, 42(2), 1963, p. 126.

[13]- Tipei, N., "Boundary conditions of a viscous flow between surfaces with rolling and sliding motion", Trans. ASME, J. Tribology, 90(1), 1968, pp. 254-261.

[14]- Cupillard, S., Cervantes, M. J. and Glavatskih, S.,"Pressure buildup mechanism in a textured inlet of a hydrodynamic contact", Trans. ASME, J. Tribology, 130(2), 2008, 021701.

[15]- Shahmohamadi, H., Rahmani, R., Rahnejat, H., Garner, C.P. and Dowson, D., "Big end bearing losses with thermal cavitation flow under cylinder deactivation", Tribology Letters, 57(1), 2015. pp. 1-7.

[16]- Shahmohamadi, H., Rahmani, R., Rahnejat, H., Garner, C.P., King, P.D., "Thermomixed hydrodynamics of piston compression ring conjunction", Tribology Letters, 51(3), 2013, pp. 323-340.

[17]- Shahmohamadi, H., Mohammadpour, M., Rahmani, R., Rahnejat, H., Garner, C.P. and Howell-Smith, S., "On the boundary conditions in multi-phase flow through the piston ringcylinder liner conjunction”, Tribology Int., 90, 2015, pp. 164-174.

[18]- Dobrica, M. B. and Fillon, M., "About the validity of Reynolds equation and inertia effects in textured sliders of infinite width", Proc. IMechE, Part J: J. Eng. Tribology., 223(1), 2009, pp. 69-78.

[19]- Haddad, S.D. and Tian, K-T., "Analytical study of offset piston and crankshaft designs and the effect of oil film on piston slap excitation in a diesel engine", Mech. Mach. Theory, 30, 1995, pp. 271-284

[20]- Tian, T., Noordzij, L. B., Wong, V. W. and Heywood, J. B., "Modelling Piston-Ring Dynamics, Blowby, and Ring-Twist Effects", Trans. ASME, J. Eng Gas Turbines \& Power, 120, 1998, pp. 843-854

[21]- Baker, C.E., Theodossiades, S., Rahnejat, H. and Fitzsimons, B., "Influence of in-plane dynamics of thin compression rings on friction in internal combustion engines", Trans. ASME, J. Eng. Gas Turbines \& Power, 134(9), 2012:092801.

[22]- Baker, C., Rahmani, R., Theodossiades, S., Rahnejat, H. and Fitzsimons, B., "On the Effect of Transient In-Plane Dynamics of the Compression Ring Upon Its Tribological Performance", Trans. ASME, J. Eng. Gas Turbines \& Power, 137(3), 2015, 032512.

[23]- Rahmani, R., Theodossiades, S., Rahnejat, H. and Fitzsimons, B., "Transient elastohydrodynamic lubrication of rough new or worn piston compression ring conjunction with an out-of-round cylinder bore", Proc. IMechE, Part J: J. Eng. Tribology, 226(4), 2012, pp. 284-305

[24]- Swift, H. W., "The stability of lubricating films in journal bearings", J. Inst. Civ. Eng., 233, Part 1, 1932, p. 267. 
[25]- Stieber, W. (1933) “Dus Schwimmlager”, Verein Deutscher Ingenieurre, 1933, Berlin.

[26]- Reynolds, O., "On the Theory of Lubrication and Its Application to Mr. Beauchamp Tower's Experiments, Including an Experimental Determination of the Viscosity of Olive Oil”, Proc. Roy. Soc. London, 40(242-245), 1886, pp. 191-203.

[27]- Gohar, R. and Rahnejat, H., "Fundamentals of Tribology", Imperial College Press, London, 2008.

[28]- Morris, N., Rahmani, R., Rahnejat, H., King, P.D. and Fitzsimons, B., “Tribology of piston compression ring conjunction under transient thermal mixed regime of lubrication” Tribology International, 59, 2013, pp.248-258.

[29]- Morris, N., Rahmani, R., Rahnejat, H., King, P.D. and Fitzsimons, B., "The influence of piston ring geometry and topography on friction", Proc. IMechE, Part J: J. Engineering Tribology, 227(2), 2013, pp. 141-153.

[30]- Ma, M.-T., Sherrington, I. and Smith, E.H., "Analysis of lubrication and friction for a complete piston-ring pack with an improved oil availability model - Part 1: circumferentially uniform film", Proc. IMechE, Part J: J. Engineering. Tribology, 211, 1997, pp. 1-15.

[31]- Akalin, O. and Newaz, G.M., "Piston ring-cylinder bore friction modeling in mixed lubrication regime: Part I-Analytical results", Trans. ASME, J. Trib., 123, 2001, pp. 211218.

[32]- Mishra, P.C., Balakrishnan, S. and Rahnejat, H., "Tribology of compression ringtocylinder contact at reversal", Proc. IMechE, Part J: J. Engineering Tribology, 222, 2008, pp. 815-826.

[33]- Etsion, I., Y. Kligerman, and A. Shinkarenko. "Improving Tribological Performance on Piston Rings by Partial Surface Texturing”, Trans. ASME, J. Trib., 123, 2005, pp.632-638.

[34]- Kawasegi, N., Sugimori, H., Morimoto, H., Morita, N. and Hori, I., "Development of cutting tools with microscale and nanoscale textures to improve frictional behaviour", Precision Engineering, 33(3), 2009, pp.248-254.

[35]- Teodorescu, M., Balakrishnan, S., and Rahnejat, H., "Integrated tribological analysis within a multi- physics approach to system dynamics", Tribology and Interface Science Series, Elsevier, 48, 2005, pp.725-737.

[36]- Briscoe, B. J. and Evans, D. C. B., "The shear properties of Langmuir-Blodgett layers", Proc. Roy. Soc., Series A: Math. and Phy. Sci, 1982, pp.389-407.

[37]- Greenwood, J. A., and Tripp, J. H., "The contact of two nominally flat rough surfaces", Proc. IMechE,, Part C; J. Mech. Engineering. Science, 185 (1), 1970-1971, pp. 625-633. 
[38]- Akalin, O. and Newaz, G.M., "Piston Ring-Cylinder Bore Friction Modeling in Mixed Lubrication Regime: Part II-Correlation With Bench Test Data", Trans. ASME, J. Tribology, 123(1), 2001, pp. 219-223.

[39]- Gore, M., Rahmani, R., Rahnejat, H. and King, P.D., "Assessment of friction from compression ring conjunction of a high-performance internal combustion engine: A combined numerical and experimental study", Proc. IMechE, Part C: J. Mechanical Engineering Science, 2016, 230(12), pp.2073-2085.

[40]- Leighton, M., Morris, N., Gore, M., Rahmani, R., Rahnejat, H. and King, P.D., "Boundary interactions of rough non-Gaussian surfaces", Proc. IMechE, Part J: J. Engineering Tribology, 2016, 230(11), pp.1359-1370.

[41]- Gore, M., Theaker, M., Howell-Smith, S., Rahnejat, H. and King, P.D., "Direct measurement of piston friction of internal-combustion engines using the floating-liner principle", Proc. IMechE, Part D: J. Automobile Engineering, 228(3), 2014, pp.344-354.

[42]- Styles, G., Rahmani, R., Rahnejat, H. and Fitzsimons, B., "In-cycle and life-time friction transience in piston ring-liner conjunction under mixed regime of lubrication", Int. J. Engine Research, 15(7), 2014, pp. 862-876. 